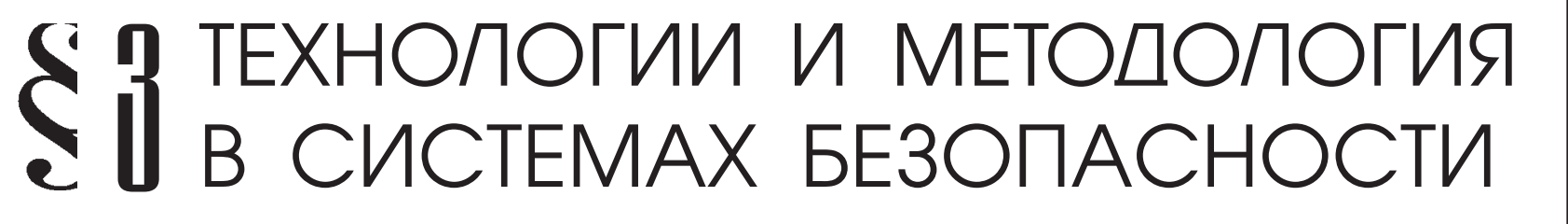

Андрощук В.В.

\section{О ВОЗМОЖНОСТИ ИСПОЛЬЗОВАНИЯ В РОССИЙСКИХ УСЛОВИЯХ ОПЫТА И РЕКОМЕНДАЦИЙ ОБЪЕДИНЕНИЙ ЗАРУБЕЖНЫХ РЕВИЗОРОВ ПО ПРОТИВОДЕЙСТВИЮ МОШЕННИЧЕСТВУ И ХИЩЕНИЯМ}

\begin{abstract}
Аннотация: Статья посвящена проблеме распространения мошенничества и хищений в международном экономическом сообществе. Корпоративное мошенничество - термин, охватываюший целый ряд таких серьёзных правонарушений, как растрата, взяточничество, подлог, вымогательство и др. Для противодействия мошенничеству возникла новая профессия ревизора по борьбе с мошенничеством и хищениями, включающая в себя широкий набор компетенций. Служебное расследование случаев мошенничества преследует единственную цель - объективно разобраться с фактами. Начиная расследование мошенничества, ревизор сначала выдвигает теорию о возможной виновности или невиновности лица, а затем пытается собрать доказательства с иелью получения фактического материала, указываюшего на то, что произошло в действительности. Расследование мошенничества требует коллективных усилий специалистов в различных сферах деятельности. Рекомендачии по противодействию мотенничеству, разработанные на основе практической деятельности ревизоров из многих стран мира, анализируются, обобщаются и представляются в виде специиального руководства, некоторые основные положения которого будут рассмотрены в настоящей статье.

Ключевые слова: моченничество, хищения, беловоротничковая преступность, Ассочиация, аудит, ревизор, финансовая безопасность, коррупиия, предпринимательская деятельность, судебно-бухгалтерская экспертиза
\end{abstract}

щё несколько десятилетий назад сложно было представить, что мошенничество получит столь широкое распространение в XXI веке и станет поистине «преступлением века». В настоящее время в международной практике не сложилось единого определения термина «мошенничество», под которым понимается целый ряд правонарушений. Это могут быть обман, растрата, взяточничество, подлог, вымогательство, хищение, сокрытие фактов, умышленное введение в заблуждение и др. Тем не менее, в широком смысле своего значения, под мошенничеством подразумевается любое преступное деяние, совершаемое с целью получения выгоды и основывающееся на обмане. В российском уголовном законодательстве под мошенничеством понимается хищение чужого имущества или приобретение права на чужое имущество путём обмана или злоупотребления доверием ${ }^{1}$.

В последнее время на российских предприятиях реального сектора экономики достаточно активно используется «Международное руководство ревизоров по борьбе с мошенничеством/ хищениями» ${ }^{2}$, которое даёт оценку внутрикорпоративному мошенничеству как явлению, наносящему значительный ущерб как национальному,

\footnotetext{
${ }^{1}$ Уголовный кодекс Российской Федерации от 13 июня 1996 г. № 63-Ф3. СТ. 159 // СПС «Гарант».

${ }^{2}$ International Fraud Examiners Manual. Austin, TX: Association of Certified Fraud Examiners, 2010.
} 
так и международному бизнесу. Развитие международных отношений привело к возникновению объективной потребности в понимании процессов, происходящих на транснациональном уровне, для своевременного выявления случаев мошенничества и успешного их расследования. Руководство содержит описание и анализ многочисленных схем мошенничества, охватывающих различные аспекты деятельности предприятий. Теоретический материал дополняется примерами из профессиональной деятельности ревизоров по борьбе с мошенничеством, схемами и актуальными статистическими данными.

По данным Ассоциации сертифицированных ревизоров по борьбе с мошенничеством (Association of Certified Fraud Examiners (ACFE)) ${ }^{3}$, ущерб от злоупотреблений, связанных с профессиональной деятельностью, только в США ежегодно превышает 900 млрд. долларов. Если к этому добавить случаи нарушения конфиденциальности, мошенничества с банковскими чеками, кредитными картами и ценными бумагами, размер ущерба достигнет $10 \%$ объёма мирового производства и будет исчисляться триллионами долларов США. Громкие дела, ставшие предметом освещения в средствах массовой информации, являются лишь «верхушкой айсберга».

Одной из основных проблем «беловоротничковой преступности» ${ }^{4}$ является её латентность. Достоянием общественности становятся лишь наиболее громкие истории, в которых применение мошеннических схем было очевидным. Тем не менее, независимо от того, каков реальный ущерб от мошенничества, его размеры выражаются в ошеломляющих цифрах. По мнению членов Ассоциации, противостоять этому могут только специально подготовленные специалисты, представители новой профессии - ревизоры по борьбе с мошенничеством, которые занимаются выявлением случаев мошенничества на основании возникающих подозрений.

\footnotetext{
${ }^{3}$ URL: http://www.acfe.com/ (дата обращения - 24.04.2013).

4 Термин «беловоротничковая преступность», введённый в 1939 г. членом Американского социологического общества Эд. Сазерлендом, означает вид преступности, совершаемой представителями государства, бизнеса, должностными лицами и чиновниками. См: Сазерленд Э.Х. Являются ли преступления людей в белых воротничках преступлениями? // Социология преступности. Современные буржуазные теории: Сборник статей $=$ The sociology of crime and delinquency: Перевод с англ. / Под ред.: Никифоров Б.С. М.: Прогресс, 1966. 368 с. С. 45-59; Sutherland, Edwin H. White Collar Crime / Foreword by Donald R. Cressey. Westport, Conn.: Greenwood Press, 1983. 272 p.
}

Ассоциация сертифицированных ревизоров по борьбе с мошенничеством на сегодняшний день объединяет более 65 тыс. членов из 150 стран мира, в т.ч. и из России 5 . Основная деятельность этих специалистов связана с выполнением весьма широкого круга служебных обязанностей. Они зависят от занимаемой должности, образования, экономической отрасли, типа организации и т.П., в которой работает ревизор. В роли ревизора могут выступать внутренние и внешние аудиторы, сотрудники служб безопасности, представители государственных организаций, специалисты по внутреннему контролю, управлению рисками и корпоративному управлению и т.д. Что касается функций ревизора по борьбе с мошенничеством, то и здесь их набор довольно широк. Ревизорам приходится проводить финансовый анализ и аудит, изучать документацию по делопроизводству и бухгалтерскому учёту. В поисках доказательств мошенничества ревизоры могут проводить опросы потенциальных свидетелей и возможных подозреваемых лиц. Иными словами, ревизоры организуют и ведут процесс выявления и предотвращения случаев мошенничества.

Опыт и навыки ревизоров по борьбе с мошенничеством дают надежду на то, что проблема «беловоротничковой преступности» в конечном итоге будет досконально изучена и взята под контроль. Разумеется, этот процесс не может быть быстрым и простым. При содействии экспертов Ассоциации сертифицированных ревизоров по борьбе с мошенничеством, было начато издание Руководства по противодействию мошенническим схемам. В руках профессиональных ревизоров оно может стать эффективным инструментом противодействия мошенничеству. Следует учесть, что деятельность ревизоров - это не то же самое, что проведение внешнего аудита или судебно-бухгалтерской экспертизы. Например, внешний аудит проводится для проверки и подтверждения правильности годовой финансовой отчётности организации профессиональным аудитором, не связанным имущественными интересами с обществом или его участниками ${ }^{6}$. Что касается судебно-бухгалтерской экспертизы, то она не относится к числу обязательных экспертиз, а назначается

\footnotetext{
${ }^{5}$ Официальный сайт Российского отделения Ассоциации специалистов по расследованию хищений / мошенничества (ACFE). URL: http://www.acfe-rus.org (дата доступа 24.04.2013)

${ }^{6}$ Гражданский кодекс Российской Федерации. Часть первая от 30 ноября 1994 г. № 51-ФЗ. Ст. 91 // СПС «Гарант».
} 


\section{Национальная безопасность 3(26) • 2013}

при необходимости прокурором, следователем или судом. Результатом судебно-бухгалтерской экспертизы становится получение ответов на ограниченное число вопросов, определённых следственными или судебными органами․ В большинстве случаев мошенничество представляет собой финансовые преступления, при расследовании которых проводится общая проверка финансовых и отчётных данных.

Именно поэтому эффективным препятствием для распространения мошенничества может стать подготовка специалистов, владеющих специальными навыками и способных реально противостоять действиям преступников. Это могут быть не только профессиональные аудиторы и бухгалтеры-криминалисты, но и адвокаты, представители правоохранительных органов. Примечателен тот факт, что первые издания Руководства по противодействию мошенничеству были рассчитаны на применение только в США, Великобритании, Канаде и Японии, где мошенничество получило наибольшее распространение. Однако вскоре «беловоротничковая преступность» приобрела транснациональный характер. Поэтому сегодня авторы Руководства по противодействию мошенническим схемам уделяют большее значение не национальным особенностям данного вида преступности, а методологии расследования мошенничества.

Специалисты Ассоциации сертифицированных ревизоров по борьбе с мошенничеством рассматривают тысячи известных мошеннических схем и методов их расследования. На основе богатого эмпирического материала была проведена следующая классификация видов корпоративного мошенничества:

- финансовые махинации (financial statement fraud);

- мошенничество с кассовыми поступлениями (cash receipts);

- мошеннические выплаты (fraudulent disbursements);

- присвоение имущества и других активов (misappropriation of inventory and other assets);

- взяточничество и коррупция (bribery and corruption);

\footnotetext{
${ }^{7}$ Инструкция о производстве судебно-бухгалтерских экспертиз в экспертных учреждениях системы Министерства юстиции СССР (утв. Минюстом СССР 2 июля 1987 г. № К-8-463); Федеральный закон от 31 мая 2001 г. №73-Ф3 «О государственной судебно-экспертной деятельности в Российской Федерации» и др.
}

- $\quad$ кража интеллектуальной собственности (theft of intellectual property);

- мошенничество в финансовых организациях (financial institution fraud);

- $\quad$ мошенничество с чеками и кредитными картами (cheque and credit card fraud);

- страховое мошенничество (insurance fraud);

- мошенничество в сфере здравоохранения (health care fraud);

- мошенничество в сфере услуг (consumer fraud);

- мошенничество с использованием компьютерной техники и Интернета (computer and Internet fraud);

- мошенничество в общественном секторе (public sector fraud) ${ }^{8}$.

Основой Руководства является изучение и анализ мошеннических схем при проведении финансовых операций. Для их расследования требуется владеть основами бухгалтерского учёта. Выявление преступлений этой группы возможно усилиями руководства и аудиторов без привлечения ревизора, потому что их совершение напрямую связано с занимаемыми в компаниях должностями. Это растраты, коррупция и мошенничество с финансовыми отчётами, которые получили распространение среди сотрудников самых различных организаций - от финансовых институтов до правительственных органов.

«Руководство ревизоров по борьбе с мошенничеством/хищениями» предлагает методологию проведения расследования, основанную на богатом практическом опыте авторов пособия. В Руководстве содержатся сведения об основных инструментах и методиках, необходимых для выявления информации и доказательств совершённого мошенничества, а также установления личности правонарушителя. Материалы подробно рассматривают процесс сбора доказательств при изучении документации и основы техники проведения опроса подозреваемых лиц. Собеседование со свидетелями позволяет уточнить информацию, которая имеется в распоряжении ревизионной группы, а также выяснить другие существенные нюансы расследуемого дела. Кроме того, изучаются приёмы анализа информации из архивных документов и из сети Интернет для сбора доказательств. Приводится описание экспертиз компьютерного оборудования для восстановления удалённых данных. Компьютерные технологии активно исполь-

\footnotetext{
${ }^{8}$ International Fraud Examiners Manual. Austin, TX: Association of Certified Fraud Examiners, 2010.
} 
зуются в деятельности современных компаний, и, к сожалению, не всегда в законных целях.

Отдельный раздел Руководства посвящён правовым аспектам проведения расследования мошенничества, с которыми приходится сталкиваться ревизору. Как уже отмечалось ранее, корпоративное мошенничество относится к транснациональным видам преступности, когда само преступление совершается на территории одних государств, а совершившие его преступники находятся на территории другого государства. Поэтому информация данного раздела обладает практической значимостью, несмотря на принадлежность Российской Федерации к иной правовой системе. Немаловажной также является информация о том, какая роль отводится ревизору по борьбе с мошенничеством во время судебного процесса.

Руководство по противодействию мошенническим схемам уделяет значительное внимание вопросам профилактики мошенничества, криминологическим и этическим сторонам данного явления. Авторами анализируются причины, по которым люди совершают мошенничество. В Руководстве даются практические рекомендации по профилактике мошеннических действий. К ним отнесены проведение активной политики по противодействию мошенничеству, своевременная оценка рисков и введение корпоративных программ соответствия сотрудников занимаемым должностям.

Руководство также уделяет внимание вопросам экспертизы мошенничества, под которой понимается методология расследования преступления от его обнаружения до устранения последствий. Результатами экспертизы становятся доказательства по делу и подготовленный отчёт. На следующем этапе предполагается участие ревизора в судебном процессе для представления полученных в процессе расследования результатов. Ревизор может также дать свои рекомендации по предотвращению мошеннических действий в дальнейшей деятельности компании.

Доказательства мошенничества, как правило, содержатся в деловой документации или могут быть получены из показаний свидетелей. Соответственно, ревизор должен знать, каким образом на законных основаниях получить доказательства и как правильнее проводить опрос свидетелей.

После сбора доказательств и опроса свидетелей ревизор готовит обстоятельный и беспристрастный отчёт, подтверждающий факты выявленного мошенничества. Данные отчёта могут использоваться ру- ководством компании, адвокатами, следователями и другими лицами для установления фактов. Ревизор занимается только сбором доказательств, но не выступает в роли судьи и не выносит решений по делу. После завершения расследования, представления собранных доказательств и подготовки отчёта, ревизор довольно часто вызывается в судебные органы в качестве свидетеля по делу. Его показания должны быть правдивы, содержательны и не содержать оценочных суждений.

Несмотря на то, что вопросы профилактики мошенничества находятся в компетенции руководства компании, ревизору следует принять активное участие в выработке правильной политики по предотвращению случаев мошенничества. Выявление мошенничества на ранней стадии является первостепенной задачей внутренних и внешних аудиторов. Тем не менее, в случае наличия признаков мошенничества, ревизор должен выполнить требуемые процедуры. Все заявления о фактах мошенничества делаются с соблюдением правовой и профессиональной этики.

Многие ревизоры по борьбе с мошенничеством имеют опыт работы в сфере бухучёта, некоторые изначально выполняли функции аудитора в своей организации. Несмотря на то, что расследование мошенничества и аудит связаны друг с другом, между ними есть ряд отличий. Например, аудит проводится на регулярной основе, и его целью является общая проверка финансовых данных. В то же время, расследование мошенничества проводится только при наличии достаточных оснований с целью получения ответов на вопросы: имел ли место случай мошенничества и кто является ответственным за него?

С расследованием мошенничества тесно связана судебно-бухгалтерская экспертиза, которая проводится бухгалтерами перед предстоящим судебным разбирательством. Задачи такой экспертизы - самые разнообразные: выявление мошенничества, проведение оценки имущества, введение процедуры банкротства. При расследовании мошенничества судебно-бухгалтерская экспертиза может проводиться не только бухгалтером, но и лицами, не имеющими никакого отношения к бухучёту. Ревизор, обладая профессиональными навыками бухучёта, ведёт поиск доказательств с учётом необходимости их последующего представления в рамках гражданского или уголовного процесса. Фактически, судебный бухгалтерский учёт является одной из составляющих частей расследования мошенничества. Он дополняет расследование, но не подменяет его. Большинство ре- 


\section{Национальная безопасность $3(26) \cdot 2013$}

визоров прибегают к судебному бухучёту, который, однако, не всегда даёт результаты, подтверждающие факт совершённого мошенничества. Впрочем, ревизоры по борьбе с мошенничеством подпадают под категорию судебных бухгалтеров, поскольку результаты большинства расследований в виде отчётов представляются в дальнейшем в качестве доказательства в рамках судебного процесса.

При проведении расследования мошенничества следует помнить, что, в отличие от других правонарушений, преступник в данном случае стремится скрыть факт совершения им мошеннических действий. Если, например, грабитель использует открытые угрозы или физическое насилие для достижения своей цели, то банковский растратчик не только тайно совершает хищение денежных средств, но дополнительно пытается скрыть следы совершённого мошенничества. По этой причине, до полного завершения расследования у ревизора нет достаточных оснований высказывать кому-либо свои подозрения о совершённом мошенничестве. Способы сокрытия мошенничества настолько многочисленны и хитроумны, что практически каждый, включая ревизора, может быть введён в заблуждение. Именно поэтому, высказанные ревизором в процессе расследования неофициальные мнения могут впоследствии стать основанием для обвинения его в необъективности, непрофессионализме и предвзятости при проведении проверки.

Служебное расследование случаев мошенничества преследует единственную цель - объективно разобраться с фактами. Ревизором обычно выдвигаются взаимоисключающие друг друга версии, которые одинаково объясняют первичную информацию: лицо не совершало противоправных действий, лицо совершало иные действия, которые имеют внешнее сходство с противоправными действиями, или лицо совершало противоправные действия. Перед тем, как озвучить свои подозрения в совершённом мошенничестве, ревизору требуется наличие убедительных доказательств преступного деяния. Установление факта мошенничества в действиях подозреваемого лица является прерогативой суда. Ревизор не должен высказывать мнение о его виновности или невиновности. Поэтому, начиная расследование мошенничества, ревизор сначала выдвигает теорию о возможной виновности или невиновности лица, а затем пытается собрать доказательства с целью получения фактического материала, указывающего на то, что произошло в действительности. Обсуждение вопроса виновности является лишь составляющей частью теории, поэтому ревизору не следует делать утверждения, которые могли бы убедить его в её верности.

Расследование мошенничества требует коллективных усилий специалистов в различных сферах деятельности. Как правило, группа по проведению внутреннего служебного расследования состоит из ревизора по борьбе с мошенничеством и аудиторов, которые помогают собрать доказательства на основе изучения внутренней документации компании, дать оценку финансовой и хозяйственной деятельности компании. Служба безопасности подключается к расследованию для проведения опросов внешних свидетелей и получения архивных и других документов от третьих сторон. В процессе расследования необходимы также консультации службы персонала, которая обеспечивает соблюдение прав сотрудников компании. Участие специалистов этой службы позволяет уменьшить возможность судебных исков со стороны сотрудника, например, за незаконное увольнение. О ходе расследования необходимо информировать представителя менеджмента компании, а в особо серьёзных случаях - представителей собственника, которые, в случае необходимости, также оказываю посильное содействие проведению расследования. Возникают ситуации, когда подозреваемый сотрудник занимает высокий пост в компании, и необходимо привлечение внешнего эксперта, не зависящего от политики компании или не подверженного угрозам со стороны руководства. Привлечённые эксперты могут иметь больший опыт проведения расследования, чем члены внутренней ревизионной группы. В большинстве случаев важно также участие юрисконсультанта, который направлял бы ход расследования, особенно, на стадиях, тесно затрагивающих юридические аспекты расследуемой проблемы.

Следует отметить, что методология расследования мошенничества требует, чтобы все действия по проверке финансово-хозяйственной деятельности проводились на законных основаниях и своевременно. При наличии веских оснований для проведения ревизии, начинают предприниматься конкретные шаги. На каждом этапе ревизии предположение о совершении мошенничества постепенно находит своё подтверждение. Как правило, беседа с подозреваемым субъектом происходит уже на завершающей стадии расследования, после того, как собранной информации и доказательств достаточно для предъявления обвинения. Разумеется, на всех этапах рас- 
следования ревизору не следует забывать о соблюдении прав заинтересованных сторон. Ревизор вправе избрать по своему усмотрению тактику очерёдности проведения тех или иных мероприятий, исходя из особенностей конкретной служебной проверки.

Если говорить о профессиональных качествах ревизора по борьбе с мошенничеством, то их перечень будет весьма широк. Помимо технических навыков, успешный эксперт способен беспристрастно выявлять факты из многочисленных свидетельских показаний. Результаты расследования должны быть безошибочными и всесторонними. Способность давать объективную оценку фактам является особенно важной. Иными словами, ревизор - всегда немного юрист, немного бухгалтер, немного криминолог, а также детектив и следователь в одном лице.

Наиважнейшим качеством для ревизора по борьбе с мошенничеством является умение общаться с людьми, с которыми он встречается в течение короткого времени и с единственной целью - получение информации. В идеале, ревизор должен привлекать и побуждать людей к тому, чтобы они стали полезными расследованию. Отношение ревизора к людям формирует их отношение к нему. Очевидная неприязнь вызовет беспокойство и тревогу у его собеседников, сделает их отстранёнными и настороженными даже в том случае, когда для этого не будет причин. Опытный ревизор редко бывает жёстким, за исключением тех случаев, когда в этом есть объективная необходимость, подобное поведение тщательно спланировано и оценены возможные последствия. Иными словами, ревизор должен быть человеком, с которым хотелось бы общаться. В поисках виновного, ревизору приходиться встречаться со многими невиновными свидетелями. Способность завязать с ними беседу является неотъемлемой составляющей методологии расследования. Поскольку свидетелями могут выступать люди разного общественного положения и рода занятий, умение устанавливать отношения со всеми ними весьма важно для успеха расследования. Нет двух одинаковых людей, поэтому важно, чтобы ревизор умел говорить на языке собеседника. Специалист с техническим образованием не будет отвечать на вопросы таким же образом, как человек с гуманитарным образованием. С каждым новым делом подход ревизора к опросу свидетелей также меняется.

Ревизор по борьбе с мошенничеством должен владеть ключевыми понятиями финансовой деятельности и уметь делать соответствующие выводы на основе её результатов. Уникальность мошенничества заключается в том, что в отличие от обычных имущественных преступлений, личность преступникамошенника обычно известна с самого начала. При расследовании ограбления банка не стоит вопрос о том, было ли совершено преступление; вопрос в том - кто совершил преступление? В случаях мошенничества проблема не только в установлении личности виновного, а в установлении в его действиях признаков мошенничества.

Важно, чтобы ревизор в своём отчёте мог представить схему мошенничества в упрощённом виде, чтобы все заинтересованные стороны смогли понять её смысл. Мошенничество со стороны выглядит сложным процессом, однако в реальности большинство мошеннических способов довольно просты. Сложными их делают методы сокрытия преступных деяний.

Таким образом, проблема мошенничества, характерная как для развитых, так и развивающихся экономик, объективно существует и в ближайшее время не исчезнет, несмотря на принимаемые на законодательном уровне меры по противодействию корпоративному мошенничеству и хищениям. С учётом разнообразия сфер и условий деятельности, ревизор по борьбе с мошенничеством должен обладать разнообразными знаниями и навыками. Многообразие схем мошенничества, тем не менее, не означает их оригинальности. Однако конкретная реализация этих схем на практике становится с каждым днём всё более искусной. Значительное число фактов мошенничества не предаётся огласке из-за угрозы ухудшения деловой репутации и потери клиентов. Именно поэтому для выполнения своих функций ревизору требуются не только профессиональные знания и практический опыт, но и определённые личные качества. Необходимо разбираться в финансовой системе и владеть информацией об известных схемах мошенничества. Ревизор должен обладать хорошо развитыми аналитическими и исследовательскими способностями, знать принципы деятельности работы компании, в которой проводится расследование.

Обращаясь к российскому опыту, следует отметить отсутствие единой системы борьбы с корпоративными преступлениями. В данных условиях большинству компаний остаётся только положиться на эффективность сотрудников службы безопасности и приглашённых аудиторов. В наиболее очевидных случаях к расследованию мошенничества привлекаются правоохранительные 
органы, чьё участие в распутывании изощрённых экономических махинаций далеко не всегда приводит к желаемому результату. Мошеннические схемы постоянно совершенствуются, а раскрываемость подобных преступлений, с учётом их специфики, остаётся на прежнем уровне. В подобных условиях деятельность специально подготовленных ревизоров по борьбе с мошенничеством становится эффективным средством обеспечения сохранности имущества и финансовых средств участников делового сообщества. В настоящее время подготовкой специалистов данного профиля занимается Ассоциация сертифицированных ревизоров по борьбе с мошенничеством (ACFE). Присваиваемая квалификация подтверждает наличие у ревизора необходимых знаний в области предотвращения, выявления и сдерживания мошенничества. Приобретённый в результате своей деятельности опыт специалисты Ассоциации обобщили и представили в «Международном руководстве ревизоров по борьбе с мошенничеством/ хищениями», поскольку процесс глобализации уже давно вывел мошенничество за рамки национальных государств и придал ему характер международной преступности.

\section{Библиография:}

1. Уголовный кодекс Российской Федерации от 13 июня 1996 г. № 63-Ф3. Ст. 159 // СПС «Гарант».

2. International Fraud Examiners Manual. Austin, TX: Association of Certified Fraud Examiners, 2010.

3. Официальный сайт Ассоциации сертифицированных ревизоров по борьбе с мошенничеством (Association of Certified Fraud Examiners (ACFE)). URL: http://www.acfe.com/ (дата обращения 24.04.2013).

4. Сазерленд Э.Х. Являются ли преступления людей в белых воротничках преступлениями? // Социология преступности. Современные буржуазные теории: Сборник статей = The sociology of crime and delinquency: Перевод с англ. / Под ред.: Никифоров Б.С. М.: Прогресс, 1966. 368 с. C. $45-59$.

5. Sutherland, Edwin H. White Collar Crime / Foreword by Donald R. Cressey. Westport, Conn.: Greenwood Press, 1983. 272 p.

6. Официальный сайт Российского отделения Ассоциации специалистов по расследованию хищений / мошенничества (ACFE). URL: http:// www.acfe-rus.org (дата доступа - 24.04.2013).

7. Гражданский кодекс Российской Федерации. Часть первая от 30 ноября 1994 г. № 51-ФЗ. Ст. $91 / /$ СПС «Гарант».

8. Инструкция о производстве судебно-бухгалтерских экспертиз в экспертных учреждениях системы Министерства юстиции СССР (утв. Минюстом СССР 2 июля 1987 г. № К-8-463).

9. Федеральный закон от 31 мая 2001 г. №73-Ф3 «О государственной судебно-экспертной деятельности в Российской Федерации» и др.

10. Кикоть-Глуходедова Т.В. Возможности использования опыта деятельности системы обеспечения внутренней безопасности США в отечественных условиях // Полицейская деятельность. - 2012. - 4. - С. $70-73$.

11. Куракин А.В., Костенников М.В. Административно-правовое противодействие коррупции в системе государственной службы и в деятельности сотрудников полиции Российской Федерации и зарубежных государств // NB: Российское полицейское право. - 2013. - 1. C. 65 - 83. URL: http://www.e-notabene.ru/pm/ article_735.html

12. Костенников М.В., Куракин А.В. Административно-правовое противодействие коррупции в системе государственной службы и в деятельности сотрудников полиции Российской Федерации и зарубежных государств. // Полицейская деятельность. $-2011 .-1$. - С. 10 - 16.

\section{References (transliteration):}

1. Sazerlend E.H. Yavlyayutsya li prestupleniya lyudey v belyh vorotnichkah prestupleniyami? // Sociologiya prestupnosti. Sovremennye burzhuaznye teorii: Sbornik statey $=$ The sociology of crime and delinquency: Perevod s angl. / Pod red.: Nikiforov B.S. M.: Progress, 1966.368 c. S. 45-59.

2. Sutherland, Edwin H. White Collar Crime / Foreword by Donald R. Cressey. Westport, Conn.: Greenwood Press, 1983. 272 p.

3. Kikot'-Gluhodedova T.V. Vozmozhnosti ispol'zovaniya opyta deyatel'nosti sistemy obespecheniya vnutrenney bezopasnosti SShA v otechestvennyh usloviyah // Policeyskaya deyatel'nost'. - 2012. - 4. - C. 70 - 73.

4. Kurakin A.V., Kostennikov M.V. Administrativnopravovoe protivodeystvie korrupcii v sisteme gosu- 
DOI: $10.7256 / 2073-8560.2013 .3 .8910$

При цитировании этой статьи сноска на dоі обязательна

Технологии и методология в системах безопасности

darstvennoy sluzhby i v deyatel'nosti sotrudnikov policii Rossiyskoy Federacii i zarubezhnyh gosudarstv // NB: Rossiyskoe policeyskoe pravo. - 2013. - 1. - C. 65 - 83. URL: http://www.e-notabene.ru/ pm/article_735.html
5. Kostennikov M.V., Kurakin A.V. Administrativno-pravovoe protivodeystvie korrupcii v sisteme gosudarstvennoy sluzhby i v deyatel'nosti sotrudnikov policii Rossiyskoy Federacii i zarubezhnyh gosudarstv. // Policeyskaya deyatel'nost'. - 2011. - 1. - C. $10-16$. 